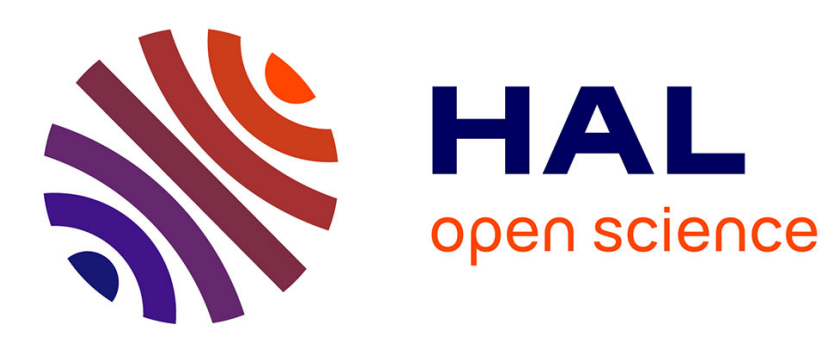

\title{
Streaming Potential and Permeability of Saturated Sandstones under Triaxial Stress: Consequences for Electrotelluric Anomalies prior to Earthquakes
}

Laurence Jouniaux, Jean-Pierre Pozzi

\section{- To cite this version:}

Laurence Jouniaux, Jean-Pierre Pozzi. Streaming Potential and Permeability of Saturated Sandstones under Triaxial Stress: Consequences for Electrotelluric Anomalies prior to Earthquakes. Journal of Geophysical Research: Solid Earth, 1995, 100;B6 (B6), pp.10197-10209. 10.1029/95JB00069 . hal00108297

\section{HAL Id: hal-00108297 \\ https://hal.science/hal-00108297}

Submitted on 5 Feb 2021

HAL is a multi-disciplinary open access archive for the deposit and dissemination of scientific research documents, whether they are published or not. The documents may come from teaching and research institutions in France or abroad, or from public or private research centers.
L'archive ouverte pluridisciplinaire HAL, est destinée au dépôt et à la diffusion de documents scientifiques de niveau recherche, publiés ou non, émanant des établissements d'enseignement et de recherche français ou étrangers, des laboratoires publics ou privés. 


\title{
Streaming potential and permeability of saturated sandstones under triaxial stress: Consequences for electrotelluric anomalies prior to earthquakes
}

\author{
Laurence Jouniaux and Jean-Pierre Pozzi \\ Laboratoire de Géologie, Ecole Normale Supérieure, Paris
}

\begin{abstract}
The streaming potential, due to fluid circulation in rock, was measured on saturated sediments (Fontainebleau sandstones). The electrokinetic coupling coefficient, which is the ratio of the streaming potential and the excess pore pressure, is proportional to the fluid resistivity. Additionally, for a fluid conductivity of $10^{-3} \mathrm{~S} / \mathrm{m}$, the electrokinetic coupling coefficient varies from 10 to $6642 \mathrm{mV} / 0.1 \mathrm{MPa}$ for sample permeability in the range of permeabilities from $0.15 \times 10^{-15}$ to $1220 \times 10^{-15} \mathrm{~m}^{2}$. The different values of the electrokinetic coupling coefficient have been explained by the effect of increasing surface conductivity which becomes nonnegligible compared to fluid conductivity for low permeability. When the sample is deformed under triaxial stress up to failure, the vertical permeability (along the principal stress) drops by about $0.20 \% / 0.1 \mathrm{MPa}$ when failure occurs. The typical variation of the electrokinetic coupling coefficient is a large increase beginning with the onset of the localization of the shear band at about $75 \%$ of the yield stress and stopping at the failure. This increase of the electrokinetic coupling coefficient is due to an increase of $\zeta$ potential in the shear zone when new surfaces are created and connected. Possible consequences of our results are given concerning the electrical fields which could appear during the preparation of an earthquake. It is shown that in some cases, self-potential anomalies reported in the deformed zone preceding an earthquake occurrence could be due to an increase of the electrokinetic coupling coefficient from $75 \%$ of the yield stress to rupture in the vicinity of one of the electrodes. Any variation of fluid resistivity or permeability in the vicinity of one electrode could change the electrokinetic coupling coefficient, inducing a surface electrokinetic potential anomaly. In regard to the interpretation of the electrokinetic effect which occurs at large distance from the epicenter, a larger electrokinetic potential anomaly could be measured between electrodes situated along a vertical fluid flow, for instance, in a shallow borehole. An electrokinetic potential anomaly up to $\mathbf{3 0}$ $\mathrm{mV}$, for a fluid conductivity of $0.01 \mathrm{~S} / \mathrm{m}$ and a rock permeability of $10^{-12} \mathrm{~m}^{2}$, could be observed with a change of the underground water table level as slight as $50 \mathrm{~cm}$ (50 mbar). Moreover, if the permeability between the electrodes is increased by a factor of $8 \times 10^{3}$, the electrokinetic coupling coefficient could be enhanced by a factor up to 650.
\end{abstract}

\section{Introduction}

Surface observations of self-potential (SP) anomalies have been reported from numerous tectonically active areas in the world. Electrotelluric precursors to earthquakes appear from a few minutes to several days before the seism and can be observed as far as $300 \mathrm{~km}$ from the epicenter, with an intensity ranging from 10 to $100 \mathrm{mV}$. The correlation of SP anomalies with earthquake occurrences has often been emphasized as a possible means for predicting earthquakes [Mizutani et al., 1976; Corwin and Morrison, 1977; Ishido and Mizutani, 1981; Varotsos and Alexopoulos, 1984a, b].

SP anomalies can be produced by a streaming potential, as a consequence of fluid pressure gradients; by a thermoelectric potential, as a consequence of a temperature gradient; by a chemical potential, as a consequence of a chemical gradient; or by these effects possibly acting together. The Copyright 1995 by the American Geophysical Union.

Paper number 95JB00069.

0148-0227/95/95JB-00069\$05.00 streaming potential effect in the crust may be a promising model to explain low-frequency electric and magnetic precursors to earthquakes. These electrokinetic effects may be produced by fluid percolation in the crust, driven by a pore pressure gradient related to precursory deformation. This model was first proposed by Mizutani et al. [1976], who assumed that dilatancy prior to earthquakes [Nur, 1972; Scholz et al., 1973] enhances the permeability of the medium and allows the fluid to flow in the vicinity of the fault. Murakami et al. [1984] reported self-potential anomalies associated with an active fault, and anomalous time variations of the self-potential in the fractured zone of an active fault preceding the earthquake occurrence were measured [Miyakoshi, 1986]. Dobrovolsky et al. [1989] proposed a long-distance elastic effect inducing the fluid flow and an electrokinetic effect near the electrodes. Bernard [1992] proposed an electrokinetic model based on the triggering of fluid instabilities by strain perturbation. However, the longdistance effects are still controversial, as their observation requires the coincidence of very favorable circumstances to 
take into account a reasonable precursory strain and the fact that no coseismic electrical anomalies are observed. Recently, some evidence of streaming potential has been reported in a study of the electrical effect of the annual variation of the water saturation of rocks in an underground quarry [Morat et al., 1992]. Electrokinetic effects were also proposed to explain the SP anomalies frequently observed in geothermal areas [Corwin and Hoover, 1979], or electrokinetic effects were used to monitor subsurface flow in geotechnical constructions [Merkler et al., 1989].

Surface electrokinetic effects, calculated for several geometries and various pore pressure source distributions, only appear near lateral heterogeneities of conductivity, permeability, or generally of the streaming coupling coefficient $C_{s}$, which is the ratio between the electrokinetic potential and the excess pore pressure [Nourbehecht, 1963; Fitterman, 1978, 1979]. The study of this electrokinetic coupling coefficient and its variation prior to earthquakes is therefore essential to quantify electrotelluric effects better. Streaming potentials refer to the electrical signals produced when a fluid flows in a porous medium, and this effect can be quantified through experimental results. Few data of geophysical interest on streaming potential are available [Somasundaran and Kulkarni, 1973; Ishido and Mizutani, 1981; Massenet and Van Ngoc, 1985; Morgan et al., 1989]. These experiments are done on crushed samples or capillaries at atmospheric pressure and could not reflect the behavior of natural rocks. We chose to measure the streaming potential on intact saturated sediments with a large range of permeabilities. As the spatial distribution of anomalies in electrotelluric potentials and geomagnetic variations is partly controlled by relative change in $C_{s}$, we must know how $C_{s}$ is affected prior to an earthquake. Particularly, is the electrokinetic coupling coefficient affected during dilatancy? As the streaming potential is expected to be proportional to the fluid pressure gradient, how is it affected by changes of permeability? The streaming potential coupling coefficient $C_{s}$ and the permeability have therefore been measured first on a series of undeformed sediments and then during the deformation of samples up to failure.

\section{Electrokinetic Phenomena}

Electrokinetic phenomena are due to the existence of an electric double layer formed at the solid/liquid interface. The currently accepted model of the rock/fluid interface is due largely to Stern [1924] [Ishido and Mizutani, 1981; Morgan et al., 1989]. The double layer is made up of a layer of ions (the Helmoltz layer) adsorbed on the surface of the rock and of a diffuse mobile layer (the Gouy-Chapman zone) extending into the liquid phase. Figure 1 depicts the potential distribution: $\Phi_{0}, \Phi_{h}$, and $\zeta$ are the potentials at distances from the surface of zero, $H$, and $S$, respectively. $H$ is the distance to the beginning of the diffuse zone. $S$ is referred to as the shear plane. Under all conditions the double layer as a whole is electrically neutral: the charge of the surface layer $C_{0}$ is equal to the sum of the charges in the diffuse zone $\left(C_{d}\right)$ and in the Helmoltz layer $\left(C_{h}\right)$, appropriate charge signs being taken into account.

When a fluid is made to flow through a porous medium, there will be an occurrence of a potential, the so-called streaming potential, across the sample, because of the relative motion between the solid and the liquid. The streaming
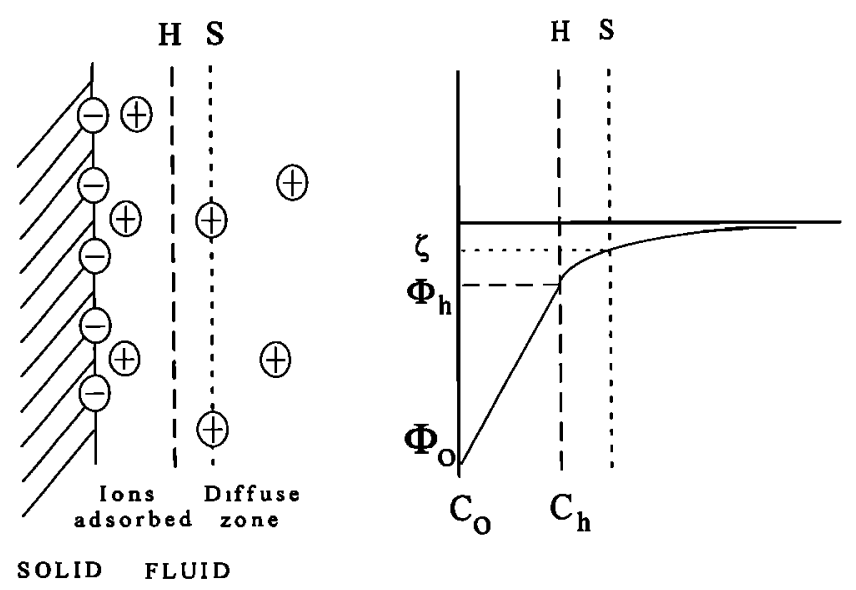

Figure 1. Scheme of the electrochemical solid/solution interface. Stern's model: $C_{0}$ is the charge density of the rock/fluid surface zone. $\Phi_{0}$ is the surface potential. $H$ is the plane between diffuse zone and adsorbed ions with a charge density $C_{h} . S$ is the slipping plane with a corresponding $\zeta$ potential. Note that $\Phi_{h}$ and $\zeta$ can be positive or negative.

potential is just the reverse of electroosmosis. $S$ is considered to be the closest plane to the surface on which fluid motion takes place. The potential on this plane is defined as the $\zeta$ potential, and it is the potential which is manifest in streaming potential measurements.

The Helmoltz-Smoluchowski equation is the relation governing the streaming potentials generated by fluids moving through porous media or capillaries [Overbeek, 1952; Nourbehecht, 1963]. In a porous medium the general relations between the electric current density $I\left(\mathrm{~A} / \mathrm{m}^{2}\right)$, the fluid flow $J(\mathrm{~m} / \mathrm{s})$, and the forces of $\operatorname{grad} V$ and $\operatorname{grad} P$ are

$$
\begin{aligned}
& -I=\frac{\sigma_{f}}{F F} \operatorname{grad} V-\frac{\varepsilon \zeta}{\eta F F^{\circ}} \operatorname{grad} P \\
& -J=-\frac{\varepsilon \zeta}{\eta F F^{\circ}} \operatorname{grad} V+\frac{k}{\eta} \operatorname{grad} P
\end{aligned}
$$

where $\sigma_{f}$ and $\varepsilon$ are the electrical conductivity and the dielectric constant of the fluid, $\zeta$ is the zeta potential, $\eta$ is the dynamic viscosity of the fluid, $k$ is the permeability of the porous medium, $F F^{\circ}$ is the formation factor $\left(\sigma_{\text {fluid }} / \sigma_{\text {rock }}\right)$ with a very high fluid conductivity when surface conduction is absent, $F F$ is the formation factor for the fluid conductivity being studied (i.e., possibly with surface conductivity), $P$ is the pressure of the fluid, and $V$ is the potential. The first term on the right-hand side of (1) represents Ohm's law and the second term in (2) represents Darcy's law. In a steady state equilibrium the convection current (due to $\operatorname{grad} P$ ) is balanced by the conduction current (due to grad $V$ ). Equating these currents leads to

$$
C_{s}=\frac{\Delta V}{\Delta P}=\frac{\varepsilon \zeta}{\eta \sigma_{f}} \frac{F F}{F F^{\circ}}
$$

which is the Helmoltz-Smoluchowski equation [Dukhin, 1974].

$\Delta V$ is the generated potential and $\Delta P$ is the applied pore pressure difference. This equation implies that the currents are of equal magnitude and opposite flow along the same 


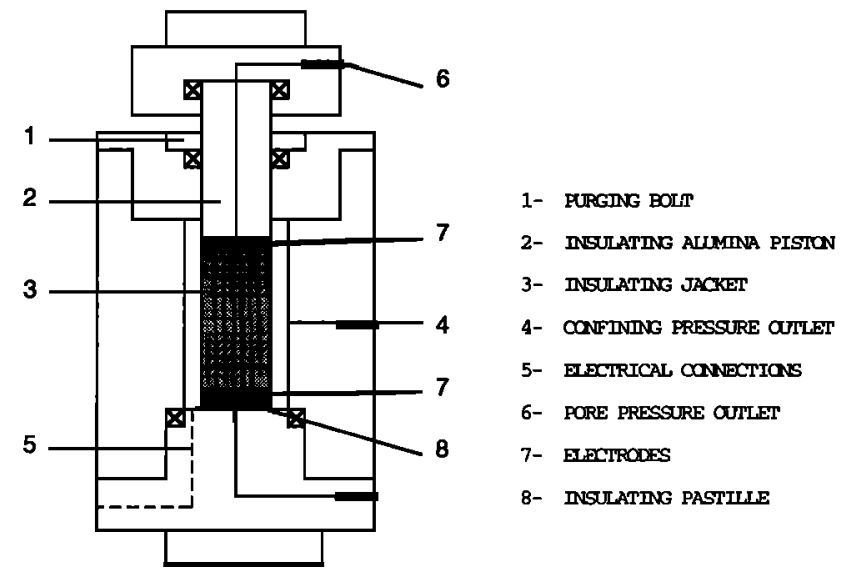

Figure 2. Nonmagnetic triaxial pressure cell and sample assembly.

path. The ratio $\Delta V / \Delta P$ is called the streaming potential cross-coupling coefficient $C_{s}$ or simply the coupling coefficient. When surface conductivity is absent, $F F=F F^{\circ}$, and we have $C_{s}=\varepsilon \zeta / \eta \sigma_{f}$. The ratio $F F^{\circ} / F F$ can be also expressed for a circular cross section pore of radius $a$ as

$$
\frac{F F}{F F^{\circ}}=1 /\left(1+\frac{2 S_{s}}{a \sigma_{f}}\right)
$$

where $\sigma_{f}$ is the fluid conductivity and $S_{s}$ is the surface conductance [Morgan et al., 1989]. We can note that the smaller the pore radius is, the greater the surface conductivity is.

\section{Experimental Procedure High-Pressure Cell}

The sample assembly is shown in Figure 2. The samples were cut in cylinders (25 mm in diameter and $50 \mathrm{~mm}$ long) and dried at $70^{\circ} \mathrm{C}$ in vacuum for 8 hours. Then they were saturated with distilled water. The samples were subjected to a gradually increasing deviatoric stress up to failure, with a confining pressure of $10 \mathrm{MPa}$. The variations of the streaming potential, of resistivity, and of permeability with deformation were measured. Each measurement required 20-40 min to reach a stable state. A typical experiment lasted 8-11 hours. We used a triaxial cell servocontrolled in displacement by an hydraulic press. The entire cell is amagnetic, and the mobile insulating piston is made of alumina and has a central circular hole (Figure 2). The deformation was measured by a displacement sensor. The deformation of the press was not negligible and was taken into account by a calibration. The variations of axial stress, confining pressure, and pore pressure are independent. The sample was isolated from the confining fluid by an insulating jacket. The flow circuit is connected, at both ends of the sample, to an upstream and a downstream reservoir volume, where two sensors monitor the fluid pressure. Different valves allow us to keep the flow circuit open or closed. Air was removed from the flow system. The fluid was made to flow through the sample in the axial direction at each triaxial state of stress in order to measure permeability and electrokinetic potential. The two electrodes are made of beryllium bronze with a hole in the center and two linked circular grooves allowing the fluid to flow uniformly in the axial direction throughout the sample. The upper and lower electrodes are isolated from the conductive press and the cell by an insulating alumina piston and insulating pastille, respectively (Figure 2). The streaming potential and the resistance of the sample can not be measured at the same time, because the impedance meter disturbs the measurement of the streaming potential. The dielectric constant of the fluid is $\varepsilon_{\mathrm{H}_{2} \mathrm{O}}$ at temperatures between $17^{\circ} \mathrm{C}$ and $24^{\circ} \mathrm{C}$. The samples used were Fontainebleau sandstones (France), with a wide range of permeabilities. Using replicas method which produces resin casts of the pore space, we observed the porous medium of samples by electron microscope analysis. A resin is used to fill the pores, and the quartz grains are then dissolved with an acid. Different pore features have thus been shown.

\section{Resistivity Measurement}

The resistance of the sample was measured by an HP 4284A impedance meter at a frequency of $4 \mathrm{kHz}$ to avoid polarizing the electrodes. The resistance of the different wires and connections is taken into account by the impedance meter. The confining fluid was checked to be nonconductive. The fluid present in the cylindrical hole of the insulating piston and insulating pastille is in contact with the sample and can provide a conduction path outside of the sample. The resistance $R_{w}$ of this exterior conduction path was measured. The effect of $\boldsymbol{R}_{w}$ is to give a conduction path between the electrodes that is parallel with the conduction path through the sample. Thus the effective resistance between the electrodes $R_{m}$ is $1 / R_{m}=\left(1 / R_{s}\right)+\left(1 / R_{w}\right)$, where $R_{s}$ is the resistance of the sample. The resistance of the sample, the resistivity of the fluid, and the streaming potential can not be measured simultaneously. During the experiment the resistance of the sample was measured just after the streaming potential measurement. We noted that the resistance of the sample changed when fluid was flowing through it. Fluid in the upstream reservoir has a constant resistivity of $2 \times 10^{3} \Omega \mathrm{m}$ in most of the cases. After flowing through the sample, fluid is usually more conductive, and we assumed that fluid resistivity after flowing through the sample was closer to fluid resistivity in the sample than fluid resistivity in the upstream reservoir. The resistivity $\rho_{w}$ of the fluid, which has flowed through the sample, was used for the calculation of $\boldsymbol{R}_{w}$ and was measured out of the cell using a conductivity cell at each triaxial state of stress, as soon as the flow was stopped. This procedure allowed us to consider the resistivity of the sample $\left(\rho_{s}\right)$ and the resistivity of the fluid $\left(\rho_{w}\right)$ approximately equal to those that were present during the streaming potential measurement.

\section{Streaming Potential Measurement}

The streaming potential was measured during fluid flow (when permeability is $>10^{-15} \mathrm{~m}^{2}$ ) by an HP $34401 \mathrm{~A}$ voltmeter with an input resistance above $10^{10} \Omega$. The electrodes and the voltmeter were linked by coaxial wires, and the ground was connected to the press to avoid electrical noise. The lower electrode was connected to the ground of the streaming potential measurement. The resistance of the water in the insulating piston $\left(R_{w}\right)$ is taken into account. Indeed, in this case, electrical current is no longer zero in the sample, and using the definition of electrokinetic coupling coefficient (equation (3)), the measured $\Delta V$ is related to the measured $\Delta P$ as 


$$
\frac{\Delta V}{\Delta P}=C_{s} /\left(1+\frac{R_{s}}{R_{w}}\right) .
$$

Data were recorded, once per second, by a PC computer with an Institute of Electrical and Electronics Engineers interface. The flow could be reversed to measure the reverse streaming potential. The electrokinetic coupling coefficient was computed from the regression coefficient of five measurements. When permeability was less than $10^{-15} \mathrm{~m}^{2}$, the streaming potential was measured during the pressure gradient diffusion.

\section{Permeability Measurement System}

Steady state flow method. The flow system was kept open at atmospheric pressure near the downstream reservoir, and the fluid was made to flow through the sample with a manual pump near the upstream reservoir. The pressure gradient $\Delta P$ across the sample was kept at a constant value. The rate of fluid flow $Q\left(\mathrm{~m}^{3} / \mathrm{s}\right)$ through the sample was measured during steady state fluid flow. The permeability $k$ is simply given by Darcy's law,

$$
Q=(k A \Delta P) /(\eta L)
$$

where $A$ is the cross-sectional area of the sample perpendicular to the direction of the flow and $L$ is its length. This method can be used to measure permeabilities greater than $10^{-16} \mathrm{~m}^{2}$. In all our experiments the fluid flow $Q$ is proportional to the pressure gradient, and permeability values are computed from the regression coefficient determined from five measurements.

Transient flow method. The flow system is kept closed at the upstream and at the downstream reservoirs. A pressure pulse $\Delta P_{0}$ (less than $10 \%$ the magnitude of the pore fluid pressure) is applied to the fluid reservoir connected to one end of the sample. The pressure gradient decay is then recorded in the fluid reservoirs at both ends of the specimen. Brace et al. [1968] analyzed the transient flow method and derived an expression for the pressure gradient as a function of time:

$$
\Delta P(t)=\frac{2 \Delta P_{0} V_{2}}{V_{1}+V_{2}} e^{-m t},
$$

where $V_{1}$ and $V_{2}$ are the upstream and downstream reservoir volumes $\left(V_{1}=V_{2}=50 \times 10^{-6} \mathrm{~m}^{3}\right.$ in our experimental setup, large compared with the sample pore volume). A plot of the decay curve in terms of $\ln (\Delta P(t))$ versus time gives a straight line with a slope $m$, and the permeability $k$ can be determined by

$$
k=\left(m \eta \beta L V_{1} V_{2}\right) /\left[A\left(V_{1}+V_{2}\right)\right]
$$

where $\beta$ is the compressibility of the pore fluid $\left(0.42 \times 10^{-9}\right.$ $\left.\mathrm{Pa}^{-1}\right)$. This method can be used to measure permeabilities in the range $10^{-16} \mathrm{~m}^{2}$ to $10^{-24} \mathrm{~m}^{2}$.

\section{Results}

We present streaming potential measurements on seven saturated samples of intact Fontainebleau sandstones with a large range of permeabilities.

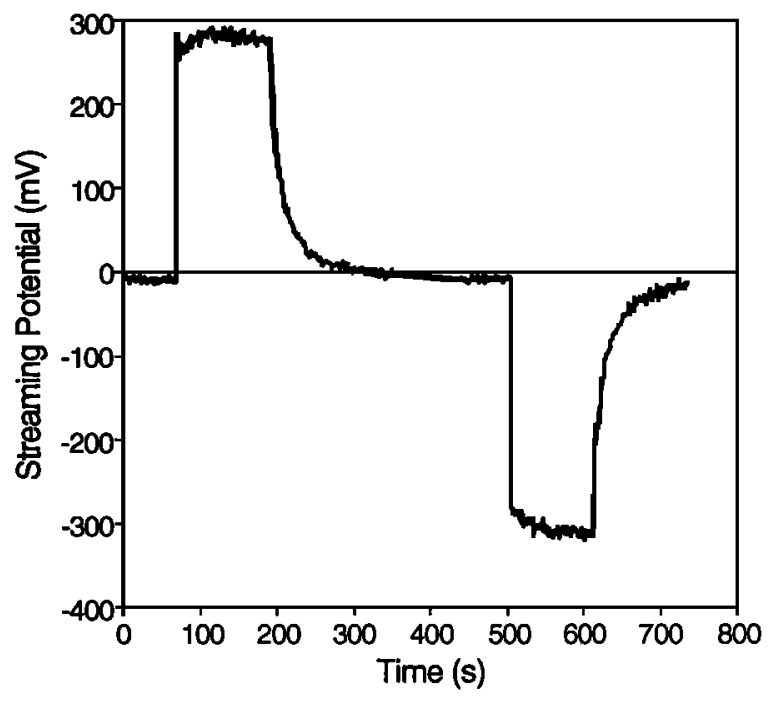

Figure 3. Example of measurement of streaming potential $\Delta V$ during a typical experiment: pressure difference $\Delta P=$ $0.1 \mathrm{MPa}$ and fluid resistivity $600 \Omega \mathrm{m}$. This measurement has been done on sample F313, with permeability $k=13 \pm 3 \times$ $10^{-15} \mathrm{~m}^{2}$, under hydrostatic pressure conditions $p=11.5$ $\mathrm{MPa}$.

\section{Results on Undeformed Sediments}

Streaming potential measurements. The streaming potential was first measured when the sample was subjected to a quasi-hydrostatic pressure of about 11.5 MPa: axial stress of $12 \pm 0.5 \mathrm{MPa}$ and confining pressure of $11 \pm 0.1 \mathrm{MPa}$. We present a typical measurement of the streaming potential when the permeability of the sample was measured using the steady state flow method (for all our samples except F82) and when the permeability was measured using the transient flow method (for F82). In all our experiments the permeability was measured along the axial stress. The effects of the surface conductivity and of the fluid conductivity on the streaming potential will be discussed. We always observed negative electrokinetic coupling coefficients; the reported values are the absolute values of the electrokinetic coupling coefficients.

A typical streaming potential $\Delta V$ at a given pressure difference $\Delta P$ is shown in Figure 3 when the permeability is measured by the steady state flow method (sample F313). The streaming potential appears when the pressure difference is applied and still remains as long as the pressure gradient is maintained. The streaming potential drops to zero when the fluid flow is stopped. The sign of the streaming potential changes when the fluid flow is reversed. For this example the resistivity of the fluid was $600 \Omega \mathrm{m}$. The streaming potential reaches about $300 \mathrm{mV}$ (Figure 3) when the pressure difference is $0.1 \mathrm{MPa}$, leading to an electrokinetic coupling coefficient $C_{s}$ of $540 \mathrm{mV} / 0.1 \mathrm{MPa}$, taking into account the resistance of the fluid in the cylindrical hole of the piston $\left(R_{w}\right)$.

The permeability of sample $F 82, k=0.15 \pm 0.05 \times$ $10^{-15} \mathrm{~m}^{2}$, was measured by the transient flow method. In this case the streaming potential was measured during the pressure gradient diffusion (Figures $4 a$ and $4 \mathrm{~b}$ ). The fluid pressure before the pressure pulse was $10.03 \mathrm{MPa}$. The fluid resistivity was $1250 \Omega \mathrm{m}$ for this example. The potential 
F82

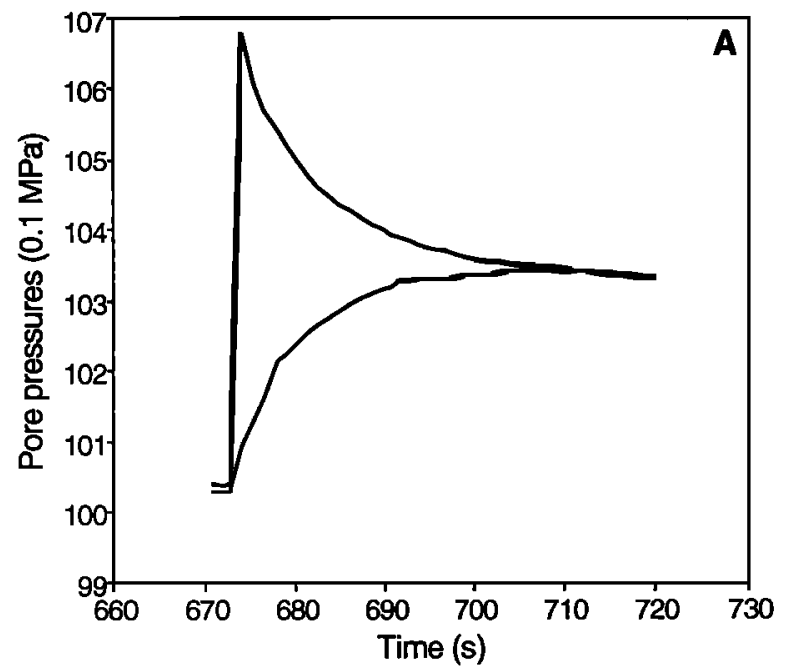

F82

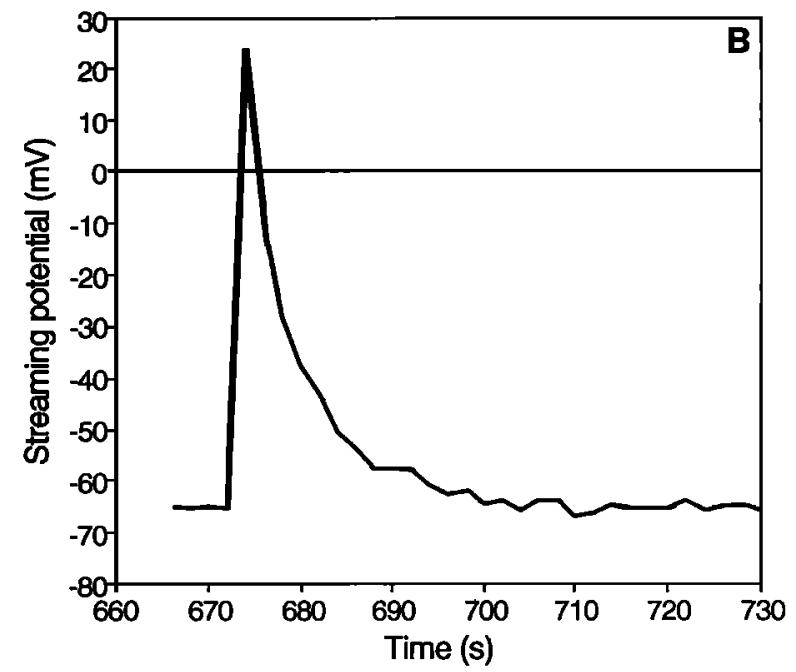

Figure 4. (a) Pressure gradient diffusion as a function of time: $\Delta P(t)$ during the transient flow method. (top) Behavior of pore pressure at the end of the sample where $\Delta P$ is applied. (bottom) Behavior of pore pressure at the other end of the sample. (b) Evolution of the streaming potential during this diffusion of pressure gradient $\Delta V(t)$. These measurements have been done on $\mathrm{F} 82$ in hydrostatic pressure conditions $p=11.5 \mathrm{MPa}$, permeability $k=0.15 \pm 0.05 \times 10^{-15} \mathrm{~m}^{2}$, fluid resistivity $\rho_{f}=1250 \mathrm{~m}$.

changes from -65 to $24 \mathrm{mV}$ (Figure $4 \mathrm{~b}$ ) when the pressure pulse is applied by increasing the pore pressure from 10.03 to $10.68 \mathrm{MPa}$ (Figure 4a). This leads to a $C_{s}$ of $13.7 \mathrm{mV} / 0.1$ $\mathrm{MPa}$ (the resistance of the fluid in the cylindrical hole of the piston $\left(R_{w}\right)$ was very large compared to the sample resistance). The evolution of the streaming potential with time is

$$
\Delta V(t)=\frac{1}{\sigma_{f}} \int_{x_{1}}^{x_{2}} i_{\text {conv }}(t) d x
$$

with $i_{\text {conv }}(t)=\sigma_{f} C_{s} \partial P(t) / \partial x$, where $x_{2}-x_{1}$ is the length of the sample. If we assume that $C_{s}$ is constant, then $\Delta V(t)=$ $C_{s} \Delta P(t)$, the pressure gradient being constant along its length, although it varies with time [Brace et al., 1968]. A typical measurement (Figures $4 \mathrm{a}$ and $4 \mathrm{~b}$ ) shows that $\Delta V$ decreases more rapidly than $\Delta P$. A possible interpretation is that the electrokinetic coupling coefficient is not exactly constant during the experiment. It seems that there is no threshold of pressure gradient to produce a streaming potential, the measurement being possible if the signal is greater than the noise.

Effect of surface conductivity. To estimate the contribution of the surface conductivity, we measured the conductivity of the sample $F 313\left(k=13 \pm 3 \times 10^{-15} \mathrm{~m}^{2}\right.$ during the entire experiment) as a function of fluid conductivity with different $\mathrm{NaCl}$ concentrations. The resistance of the sample was measured as soon as the flow was terminated. The conductivity of the sample as a function of fluid conductivity is shown in Figure 5.

The results lead to $F F^{0}=91$ when fluid conductivity is larger than $2 \times 10^{-3} \mathrm{~S} / \mathrm{m}$. For fluid conductivity below $\sigma_{f}=$ $2 \times 10^{-3} \mathrm{~S} / \mathrm{m}$ the conductivity of the sample is no longer proportional to the fluid conductivity. Our measurements are usually done with $\sigma_{f}=10^{-3} \mathrm{~S} / \mathrm{m}$ and $F F=61$, and we would have to multiply the "apparent" $\zeta$ potential by 1.5 if we wanted to have the "true" value of $\zeta$ for this sample (equation (3)).
The surface conductivity is the limit of the conductivity of the sample when fluid conductivity becomes very low. With the lowest fluid conductivity used in our measurements (Figure 5) being $10^{-3} \mathrm{~S} / \mathrm{m}$, the conductivity of the sample with this fluid allows us to overvalue the surface conductance: $S_{s}=10^{-7} \Omega^{-1}$. For sandstones the pore radius is expected to be equal to $10^{-5} \mathrm{~m}$. Then $2 S_{s} / a=2 \times 10^{-2}$ $\mathrm{S} / \mathrm{m}$ is larger than the fluid conductivity $\sigma_{f}=10^{-3} \mathrm{~S} / \mathrm{m}$ for this sample, and the surface conductivity term is the major contributor to the streaming potential.

Effect of fluid conductivity. We measured $C_{s}$ with different $\mathrm{NaCl}$ concentrations (Figure 6) with $\mathrm{pH}=5$ on the same sample $F 313$. Different pore fluids were made to flow

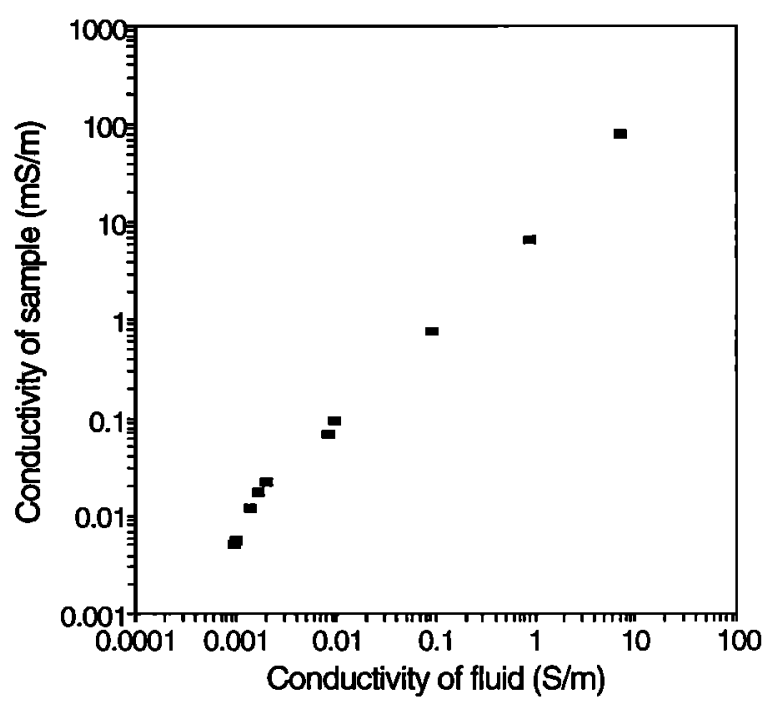

Figure 5. Rock conductivity versus fluid conductivity measured on sample F313 in hydrostatic pressure conditions $p=11.5 \mathrm{MPa}$. 


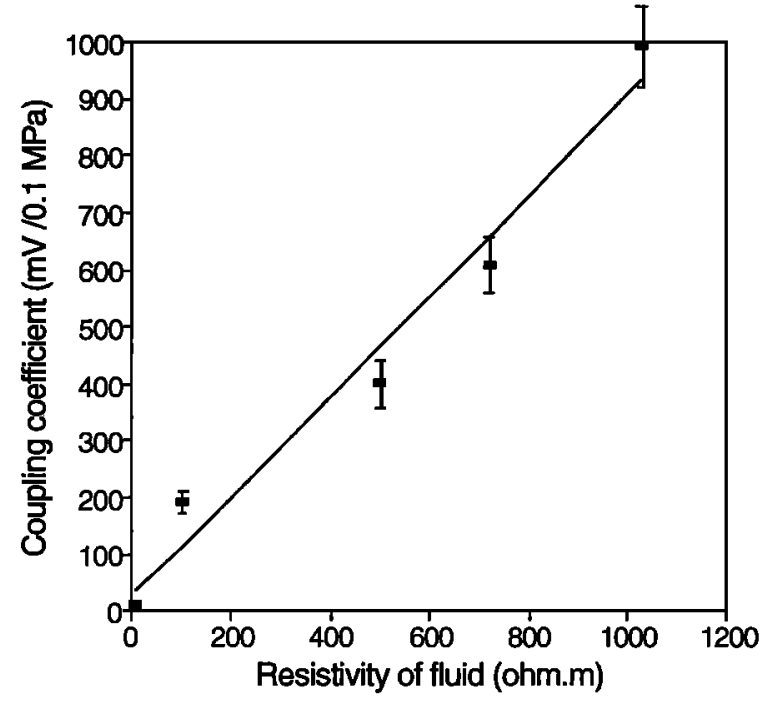

Figure 6. Electrokinetic coupling coefficient as a function of fluid resistivity for sample F313 in hydrostatic pressure conditions $p=11.5 \mathrm{MPa}$.

through the sample from the most resistive to the most conductive fluid, waiting to reach a constant fluid resistivity out of the cell at each measurement of the streaming potential. We observed electrical instabilities when fluid conductivity was higher than $10^{-2} \mathrm{~S} / \mathrm{m}$. The electrokinetic potential was no longer constant when pore pressure difference was constant and abnormal variations at higher frequency up to $50 \%$ of the signal were observed. We used distilled water to avoid these electrical instabilities. The high fluid resistivity used enhances the chemical reactions between the matrix and the fluid. Changes in fluid resistivity when the fluid was made to flow through the sample were noted outside the cell, particularly before the failure. These changes resulted from the interaction between the rock and the fluid, and this interaction was dependent on deformation and cracking. The coupling coefficient was found to be proportional to the resistivity of the fluid which allowed us to compute electrokinetic coupling coefficients at a given fluid conductivity. As $\varepsilon$ and $\eta$ are constant, we can deduce that the $\zeta$ potential is constant, in first approximation, with different salinities of fluid. Notice that for pure quartz $\zeta=-2.8 \times 10^{-2}$ to $2.5 \times$ $10^{-2} \log _{10} \rho_{f}$, it means $\zeta=-100 \mathrm{mV}$ for a fluid resistivity of $10^{3} \Omega \mathrm{m}$ and $\zeta=-50 \mathrm{mV}$ for a fluid resistivity of $10 \Omega \mathrm{m}$ [Pride and Morgan, 1991]. Moreover, Ishido and Mizutani [1981] found that $\zeta$ potential was dependant upon chemistry of the pore fluid. Nevertheless, it seems that $\zeta$ potential is constant with different conductivities for this sample and in this range of fluid conductivity. The linear dependence of the streaming potential versus the pressure gradient shows that (3) is verified with the term $F F /\left(\sigma_{f} F F^{\circ}\right)$ constant.

Relation between the streaming potential, fluid flow, and permeability. The relation between the streaming potential and the driving pressure, at a stress of about $11.5 \mathrm{MPa}$, was examined first and is shown in Figure 7. For sample F82 the slope of the straight line results from 10 measurements of pressure gradients and streaming potentials by the transient flow method, in the range $0.12-0.80 \mathrm{MPa}$. The slopes of the straight lines for the other samples result from five to seven measures by the steady state flow method. The various

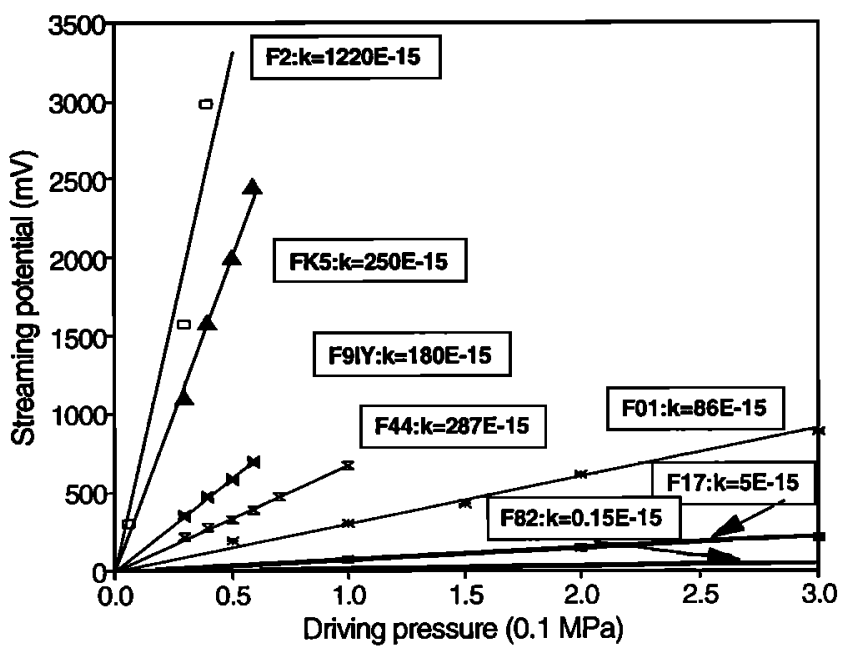

Figure 7. Streaming potential $\Delta V$ measurements with different applied driving pore pressures $\Delta P$, on seven samples, in hydrostatic pressure conditions $p=11.5 \mathrm{MPa}$. Permeabilities range from $0.15 \pm 0.05 \times 10^{-15}$ to $1220 \pm 30 \times$ $10^{-15} \mathrm{~m}^{2}$, corrected for a constant fluid resistivity $\rho_{f}=10^{3}$ $\mathbf{\Omega}$. The streaming potential is proportional to the driving pore pressure. The electrokinetic coupling coefficient $\Delta V / \Delta P$ (in absolute value) varies from $10 \pm 1$ to $6642 \pm 611$ $\mathrm{mV} / 0.1 \mathrm{MPa}$.

coupling coefficients were not measured with exactly the same fluid resistivity. As the coupling coefficients are proportional to the fluid resistivity, in first approximation they can be computed at a fixed fluid conductivity and then compared (Figure 7). There is a linear relation between the streaming potential and the driving pressure. It means that for a given sample the streaming potential is proportional to the flow rate of fluid. The coupling coefficient $C_{s}$, reported for a water resistivity of $10^{3} \Omega \mathrm{m}$, varies from $10 \pm 1$ to $6642 \pm 611 \mathrm{mV} / 0.1 \mathrm{MPa}$.

For various samples (with $\varepsilon=7.04-7.18 \times 10^{-10} \mathrm{~F} / \mathrm{m}$, $\eta=0.951-1.049 \mathrm{mPa} \mathrm{s}, \sigma_{f}=10^{-3} \mathrm{~S} / \mathrm{m}$ ), large values of the streaming coupling coefficient are obtained for large permeabilities (Figures 7 and 8a). The streaming coupling coefficient shows a linear variation with permeability on log-log coordinates with a slope of 0.7 (Figure 8a). The different values observed for the coupling coefficient could be produced by the $\zeta$ potential variations. But the $\zeta$ potential is expected to be of the same order of magnitude for all these Fontainebleau sandstones because the mineralogy is nearly identical. The apparent dependence of the coupling coefficient on permeability could be mainly due to the surface conduction effect, as the smaller the permeability is, the smaller the pore sizes in sandstones are expected to be. If surface conductivity is enhanced by smaller permeabilities, the conduction current tends to increase. As the conduction current equilibrates the convection current (which is constant), the electrical gradient tends to decrease, and the streaming coupling coefficient is decreased. This study has shown, using replicas method, different porous features reported in Table 1 . These samples do not contain clay and have comparable size quartz grains ranging between 100 and $300 \mu \mathrm{m}$. Moreover, it has been shown that the surface conductivity for sample F313 $\left(k=13 \pm 3 \times 10^{-15} \mathrm{~m}^{2}\right)$ is not negligible compared with the fluid conductivity. In order 

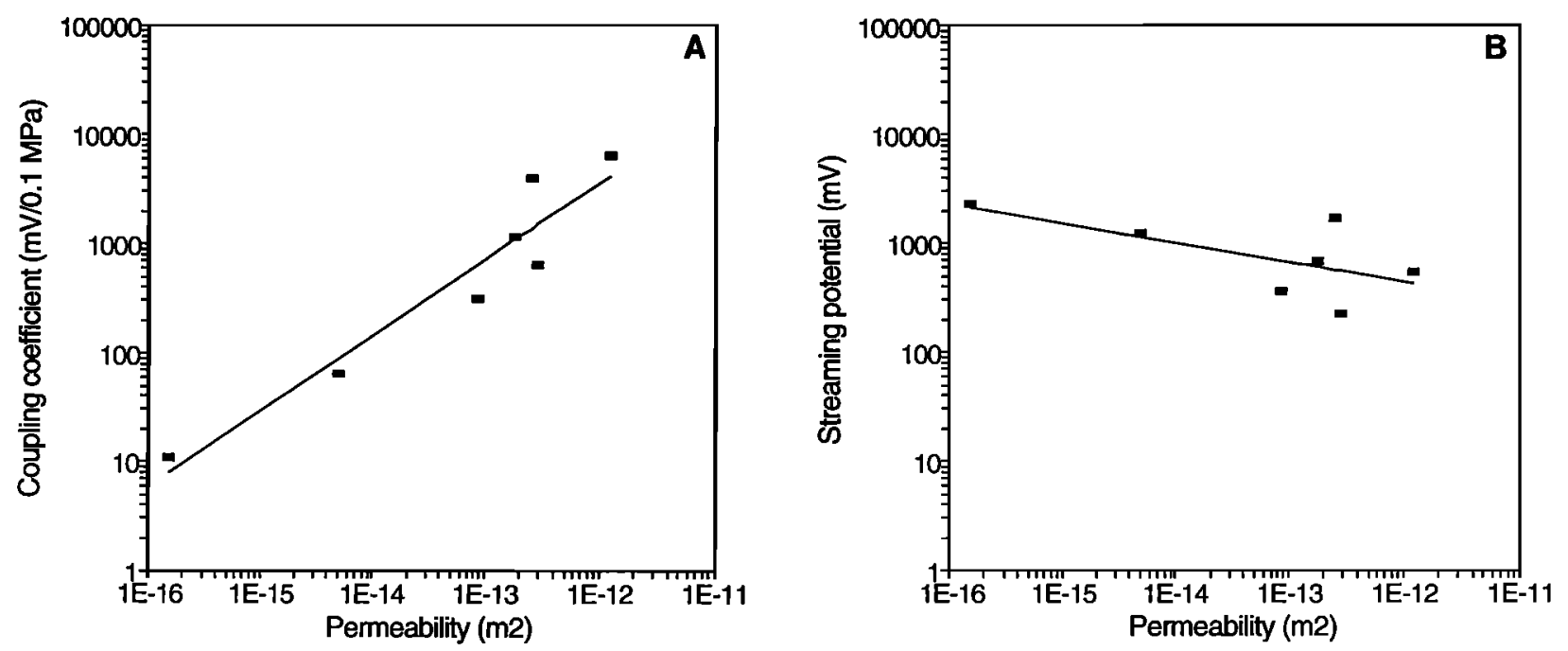

Figure 8. (a) Streaming coupling coefficient as a function of permeability. (b) Relation between the streaming potential and permeability at a constant fluid flow $Q=10^{-7} \mathrm{~m}^{3} / \mathrm{s}$, calculated (solid line) with $\zeta=-21.9 \mathrm{mV}$, fluid conductivity $\sigma_{f}=10^{-3} \mathrm{~S} / \mathrm{m}$, or measured (rectangles) for different samples.

to know the exact effect of surface conductivity and the corrected $\zeta$ potential, the rock conductivity as a function of the fluid conductivity should be measured for each sample, which is beyond the scope of this paper. Our purpose is not to calculate the exact value of $\zeta$ potential for each sample but to know how the coupling coefficient varies with permeability. The coupling coefficient varies when the permeability changes as shown in Table 1 and in Figures 7 and 8a. The effect of surface conductivity has been quantified using a capillary model to express surface conductivity as a function of surface conductance and hydraulic radius. Then hydraulic radius has been related to permeability using CarmanKozeny's law and computed values of streaming coupling coefficient are a good approximation of measured values.

We can deduce from (3) and (5) the relation between the streaming potential, the fluid flow, and the permeability [Jouniaux and Pozzi, 1995]:

$$
\Delta V=\frac{L \varepsilon \zeta Q F F}{A \sigma_{f} k F F^{\circ}}
$$

Table 1. Porosity, Permeability, and Electrokinetic Coupling Coefficient on Undeformed Sandstones

\begin{tabular}{lccc}
\hline & Permeability, & $\begin{array}{c}\text { Electrokinetic } \\
\text { Coupling } \\
\text { Coefficient, mV/0.1 } \\
\text { MPa }\end{array}$ \\
\hline F82 & Porosity, \% & $\begin{array}{c}-15 \\
\mathrm{~m}^{2}\end{array}$ & $10 \pm 1$ \\
F17 & & $0.15 \pm 0.05$ & $65 \pm 5$ \\
F01 & $13.9 \pm 1.2$ & $310 \pm 24$ \\
F44 & $96 \pm 2$ & $661 \pm 53$ \\
F9IY & $9.9 \dagger$ & $180 \pm 4$ & $1166 \pm 93$ \\
FK5 & 10 & $250 \pm 5$ & $4002 \pm 320$ \\
F2 & $20 \ddagger$ & $1220 \pm 30$ & $6642 \pm 611$ \\
\hline
\end{tabular}

With a fluid resistivity of $10^{3} \Omega \mathrm{m}$.

*Pore size 5-15 $\mu \mathrm{m}$ grain boundary porosity, important cementation.

$\dagger$ Pore size $10-30 \mu \mathrm{m}$ grain boundary porosity, no cementation.

$\ddagger$ Pore size $30-50 \mu \mathrm{m}$ large pores connected between poorly cemented grains.
The streaming potential $\Delta V$ increases if permeability decreases for a given fluid flow $Q$ (the parameters $L, A, \varepsilon, \sigma_{f}$, and $F F / F F^{\circ}$ being constant), considering $\zeta$ constant. The dependence of $\Delta V$ at $Q=10^{-7} \mathrm{~m}^{3} / \mathrm{s}$ and $\sigma_{f}=10^{-3} \mathrm{~S} / \mathrm{m}$ with permeability $k$ is shown in Figure $8 b$. The streaming potential $\Delta V$ shows a linear variation versus permeability on $\log -\log$ coordinates of $-\mathbf{0 . 1 8}$ slope with an average value of $\zeta$ of $-21.9 \mathrm{mV}$ (solid line). The difference between measurements (rectangles) and calculated variation (solid line) could be due to the different effects of surface conductivity, as explained above. The streaming potential is proportional to the fluid flow $Q$ (with $L, A, \varepsilon, \zeta, \sigma_{f}$, and $F F / F F^{\circ}$ constant) at a given permeability $k$, according to (9). We calculated the Darcian speed $Q / A$ corresponding to the pore pressure gradient of $\Delta P=0.1 \mathrm{MPa}$ for two samples. The samples F82 and $F 2$ have a permeability of $0.15 \pm 0.5 \times 10^{-15} \mathrm{~m}^{2}$ and $1220 \pm 30 \times 10^{-15} \mathrm{~m}^{2}$, respectively. The deduced Darcian speed is $9.1 \mathrm{~m} / \mathrm{yr}$ for $F 82$ and $215 \mathrm{~m} / \mathrm{d}$ for F2 which is higher than Darcian speeds in many geophysical contexts. The streaming potential as a function of Darcian speed depends on sample size, and we will not use this expression to predict the observed SP in the field. Note that electrokinetic coupling coefficient is independent of sample size and can be used for field measurements interpretation.

\section{Results on Deformed Sediments}

We present the behavior of the electrokinetic coupling coefficient and of permeability with deformation for three samples of Fontainebleau sandstones: F44, FK5, and F91Y. We first present the mechanical behavior, then the behavior of the electrokinetic coupling coefficient with deformation, and finally the behavior of permeability with deformation. The different features of the samples are reported in Tables 2 and 3 . The effects of the deformation on these parameters for the three samples will be discussed, and we will try to explain the common features of the behavior of electrical properties and of permeability with deformation.

Mechanical behavior. The stress-strain curves for the samples F44, FK5, and F9IY are represented in Figures 9a, $9 \mathrm{~b}$, and $9 \mathrm{c}$, respectively. The samples were subjected to an 
Table 2. Principal Mechanical Features of the Samples F44, FK5, and F9IY

\begin{tabular}{lcccc}
\hline & $\begin{array}{c}\text { Strain } \\
\text { Rate, s }\end{array}$ & $\begin{array}{c}\text { Yield Stress, } \\
\mathbf{M P a}\end{array}$ & $\begin{array}{c}\text { Deformation } \\
\text { at Yield } \\
\text { Stress, \% }\end{array}$ & $E, \mathbf{M P a}$ \\
\hline F44 & $9.5 \times 10^{-7}$ & 235 & 1.72 & 21,330 \\
FK5 & $8.3 \times 10^{-7}$ & 260 & 1.52 & 28,870 \\
F9IY & $8.1 \times 10^{-7}$ & 249 & 1.50 & 27,450 \\
\hline
\end{tabular}

$E$ is the Young's modulus.

increasing hydrostatic pressure up to $10 \mathrm{MPa}$ (point $\mathrm{A}$ ). Then the axial pressure was gradually increased with a constant confining pressure of $10 \pm 0.1 \mathrm{MPa}$. The average strain rate was between 8 and $9.5 \times 10^{-7} \mathrm{~s}^{-1}$. Failure occurred at a yield stress of about $250 \mathrm{MPa}$ (point $\mathrm{D}$ ). Young's modulus $E$, computed on the linear part of the curve, is between 21,000 and 29,000 MPa (Table 1).

Behavior of electrical properties with deformation. Previous studies on the same samples showed that electrical resistivity of the sample increases up to point $\mathrm{C}$, which corresponds to $47 \%, 39 \%$, and $40 \%$ of the yield stress for F44, FK5, and F9IY, respectively, and then decreases from point C to point D [Jouniaux et al., 1992].

The variation of the coupling coefficient $\Delta V / \Delta P$, reported for a fluid resistivity of $10^{3} \Omega \mathrm{m}$, during the deformation of the samples F44, FK5, and F9IY is represented in Figures $10 \mathrm{a}, 10 \mathrm{~b}$, and $10 \mathrm{c}$, respectively. The coupling coefficient decreases from point $C$ to point $L$ by $15.8 \%$ for $F 44,45.2 \%$ for FK5, and $52 \%$ for F9IY. The coupling coefficient increases from point $L$ to point $D$ with a rate of $0.07-0.19 \% / 0.1$ $\mathrm{MPa}$. The minimum value of the coupling coefficient, noted by point $L$, is obtained for a stress of $72-86 \%$ of the yield stress (Table 2).

Behavior of permeability with deformation. The permeability of the samples F44, FK5, and F9IY was measured by the steady state flow method, and its behavior with deformation is represented in Figures 11a, 11b, and 11c, respectively. First, the vertical permeability decreases (up to point C) by $0.007 \% / 0.1 \mathrm{MPa}, 0.013 \% / 0.1 \mathrm{MPa}$, and $0.027 \% / 0.1$ MPa for F44, FK5, and F9IY (Figures 11a, 11b, and 11c). Then the permeability is changed by $0.0045 \% / 0.1 \mathrm{MPa}$, $-0.011 \% / 0.1 \mathrm{MPa}$, and $-0.014 \% / 0.1 \mathrm{MPa}$ for F44, FK5, and F9IY, respectively. Permeability dropped when failure occurred, with a rate of $0.017-0.020 \% / 0.1 \mathrm{MPa}$ (Table 3).

\section{Discussion}

\section{Behavior of the Rock Resistivity with Deformation}

Changes in the fluid resistivity for fluid that has flowed through the sample result from interaction between the rock and the fluid. Resistivity of the fluid often decreases from $50 \%$ of yield stress up to failure [Jouniaux, 1994]. A whiteish water was even sometimes observed just before the failure, denoting fine particles drained from the matrix. This effect can drastically affect the resistivity of the fluid up to $57 \%$ in some cases. These interactions are enhanced by our particular procedure of using a drained sample which is necessary to perform measurements of the streaming potential and of the permeability.

Variations of the sample resistivity are partly due to changes of the fluid resistivity. However, changes of the sample resistivity are mainly due to the closure of pores and subhorizontal microcracks (up to point $\mathrm{C}$ ) and to the aperture of subvertical microcracks at the onset of dilatancy (from point $\mathrm{C}$ to point D) [Brace and Orange, 1968; Brace, 1975]. Indeed, the principal stress is always the vertical stress, and the increase of the deviatoric stress during the deformation induces the aperture of microcracks in the direction of the vertical stress. As a result the evolution of sample resistivity is the same in all our experiments, showing an increase up to point $C$ and a decrease till the failure, although the magnitude of changes in fluid resistivity may be different [Jouniaux et al., 1992; Jouniaux, 1994].

Studies done on Fontainebleau sandstones have shown brittle behavior [Darve, 1992] and an important dilatancy occurring at about $65 \%$ of the yield stress when the confining pressure is $10 \mathrm{MPa}$ [Kondo et al., 1991]. Point C, denoting the maximum resistivity of the rock during the deformation, occurs at $40-50 \%$ of the yield stress. These results are consistent with those of Brace and Orange [1968], who showed that maximum resistivity could occur before dilatancy detection.

\section{Behavior of Permeability With Deformation}

The changes of permeability are not similar for the three samples (Figures 11a, 11b, and 11c). At the beginning of the experiment, there is a path for the vertical fluid flow. First, the closure of pores and subhorizontal microcracks (up to point C) decreases the vertical permeability (Figures 11a, $11 \mathrm{~b}$, and 11c). Then the aperture of subvertical microcracks (from point $\mathrm{C}$ to point $\mathrm{D}$ ) changes the permeability by increasing or decreasing it a little. The opened subvertical microcracks (after point $\mathrm{C}$ ) do not strongly affect permeabil-

Table 3. Principal Features of the Behavior of Permeability and Electrokinetic Coupling Coefficient With Deformation

\begin{tabular}{|c|c|c|c|c|c|c|}
\hline & $\underset{k \times \mathrm{m}^{2}}{\text { Point } \mathrm{A}_{13}^{-13}}$ & $\begin{array}{c}\text { Point A } \\
C_{s}, \\
\mathrm{mV} / 0.1 \\
\mathrm{MPa}\end{array}$ & $\begin{array}{l}\text { Point C, } \\
\text { Percent of } \\
\text { Failure }\end{array}$ & $\begin{array}{l}\text { Point } L \text {, } \\
\text { Percent of } \\
\text { Failure }\end{array}$ & $\begin{array}{l}\text { Increase Rate of } \\
C_{s} \text { per } 0.1 \mathrm{MPa} \\
\text { From } \mathrm{L} \text { to } \mathrm{D}, \%\end{array}$ & $\begin{array}{c}\text { Decrease Rate } \\
\text { of } k \text { at Failure } \\
\text { per } 0.1 \mathrm{MPa} \text {, } \\
\%\end{array}$ \\
\hline $\begin{array}{l}\text { F44 } \\
\text { FK5 } \\
\text { F9IY }\end{array}$ & $\begin{array}{l}3.08 \pm 0.08 \\
2.48 \pm 0.06 \\
1.77 \pm 0.04\end{array}$ & $\begin{aligned} 531 & \pm 42 \\
4997 & \pm 399 \\
1147 & \pm 92\end{aligned}$ & $\begin{array}{l}47 \\
39 \\
40\end{array}$ & $\begin{array}{l}72 \\
86 \\
73\end{array}$ & $\begin{array}{l}0.07 \\
0.13 \\
0.19\end{array}$ & $\begin{array}{l}0.017 \\
0.020 \\
0.020\end{array}$ \\
\hline
\end{tabular}

Points A, C, L, and D refer to stress-strain curves given in Figures 9a, 9b, and 9c for samples F44, FK5, and F9IY, respectively. Increase rate of $C_{s}$ and decrease rate of $k$ are given for $0.1-\mathrm{MPa}$ change in axial stress. 
F44

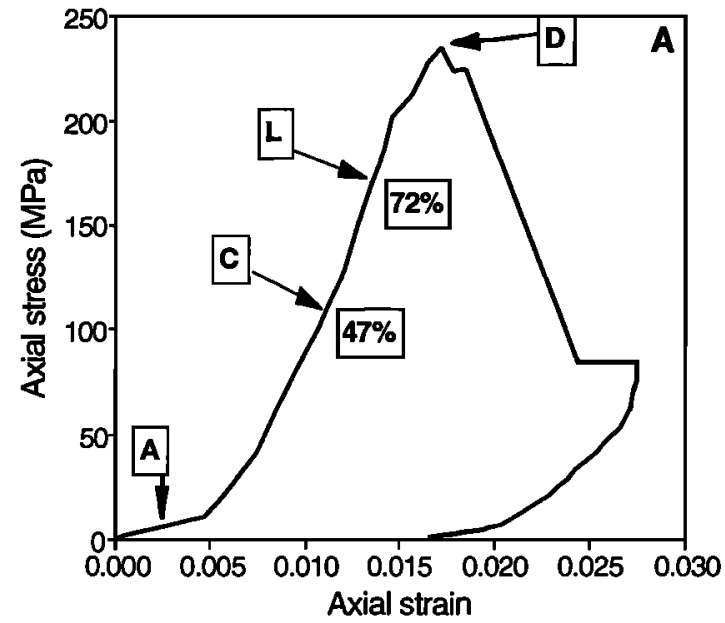

FK5

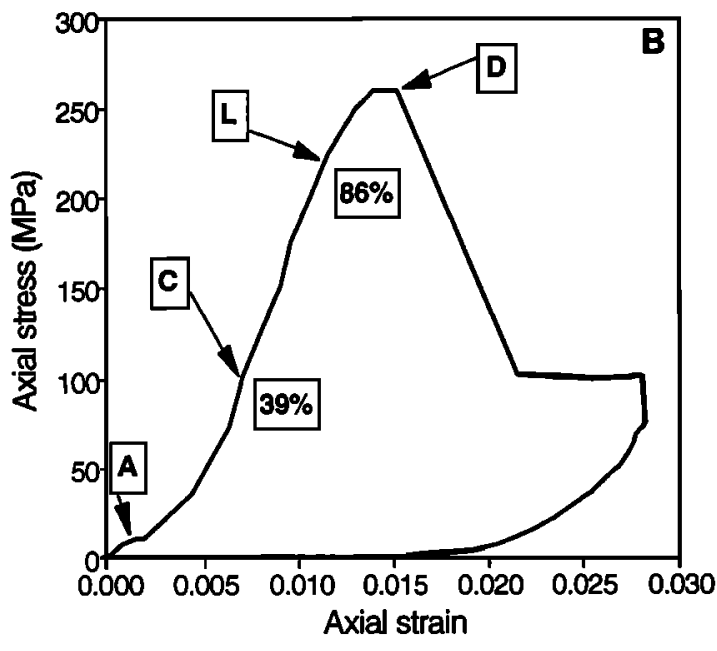

F9lY

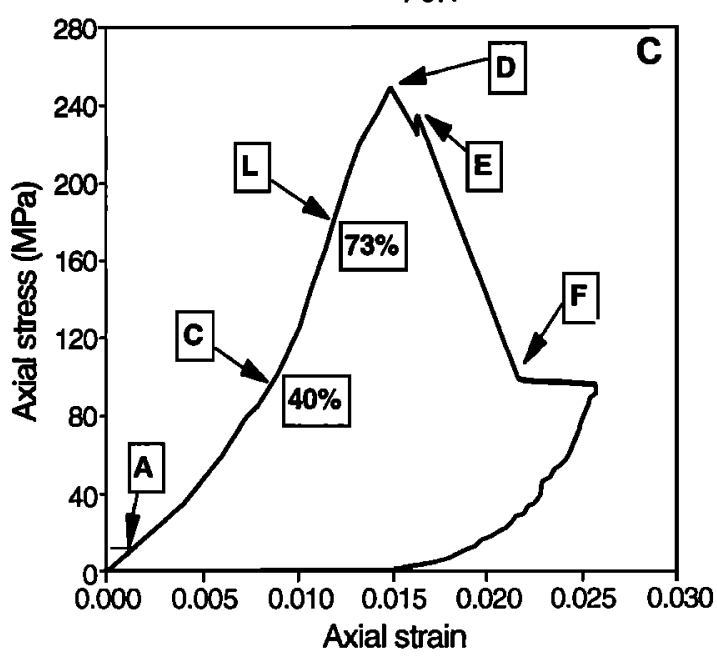

Figure 9. Axial stress-strain curve from triaxial deformation experiment to failure using a servocontrolled press in displacement. A indicates the point where samples were subjected to an increasing hydrostatic pressure up to $10 \mathrm{MPa}, \mathrm{C}$ indicates the point of maximum resistivity, $L$ indicates the point of minimum electrokinetic coupling coefficient, D indicates the point of failure, $E$ indicates Young's modulus computation point, $F$ indicates the end of the first part of the weakening state, and percentages indicate percentages of strength. (a) Results for F44. (b) Results for FK5. (c) Results for F9IY.
F44

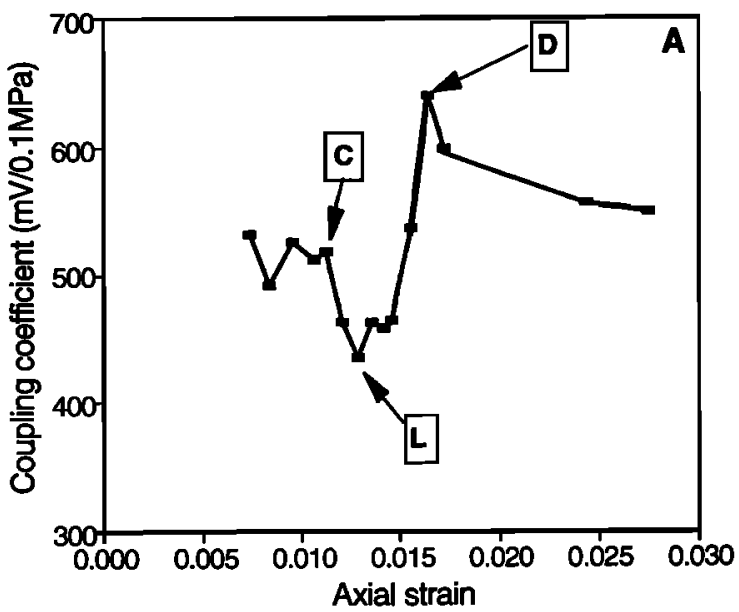

FK5

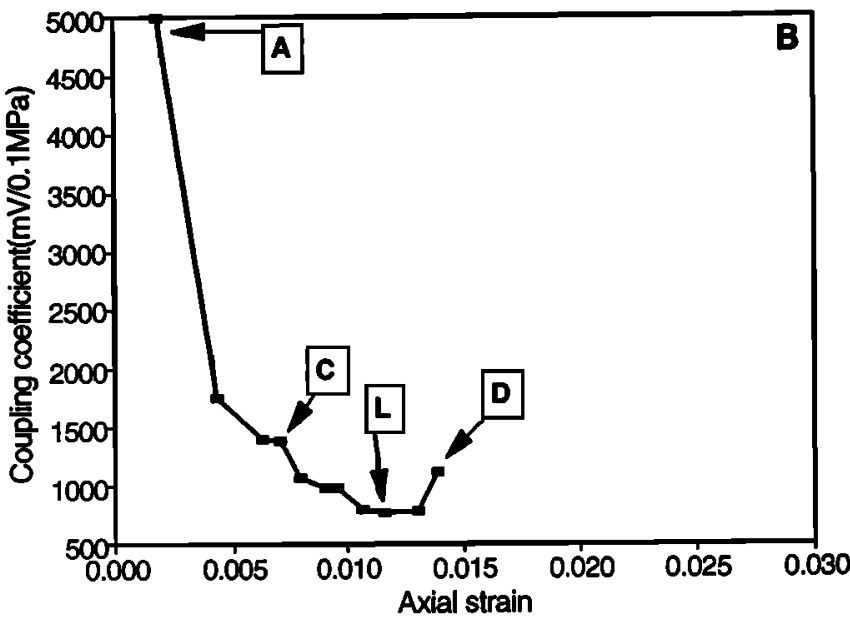

F9IY

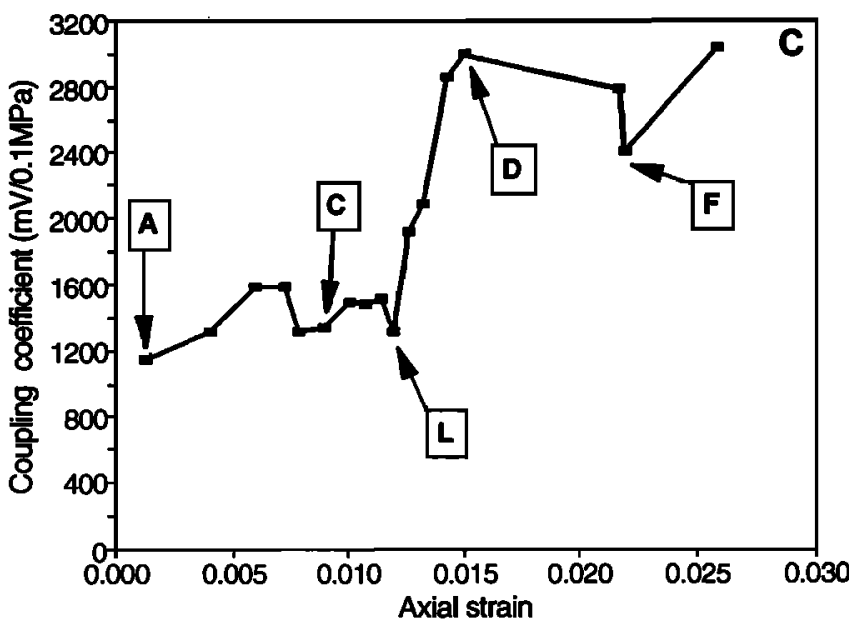

Figure 10. Variation in electrokinetic coupling coefficient (in absolute value) with the axial strain from triaxial deformation experiment to failure. $A$ indicates the point where samples were subjected to an increasing hydrostatic pressure up to $10 \mathrm{MPa}, \mathrm{C}$ indicates the point of maximum resistivity, $\mathbf{L}$ indicates the point of minimum electrokinetic coupling coefficient, $D$ indicates the point of failure, $F$ indicates the end of the first part of the weakening state, and percentages indicate percentages of strength. (a) Results for F44. (b) Results for FK5. (c) Results for F9IY 
F44

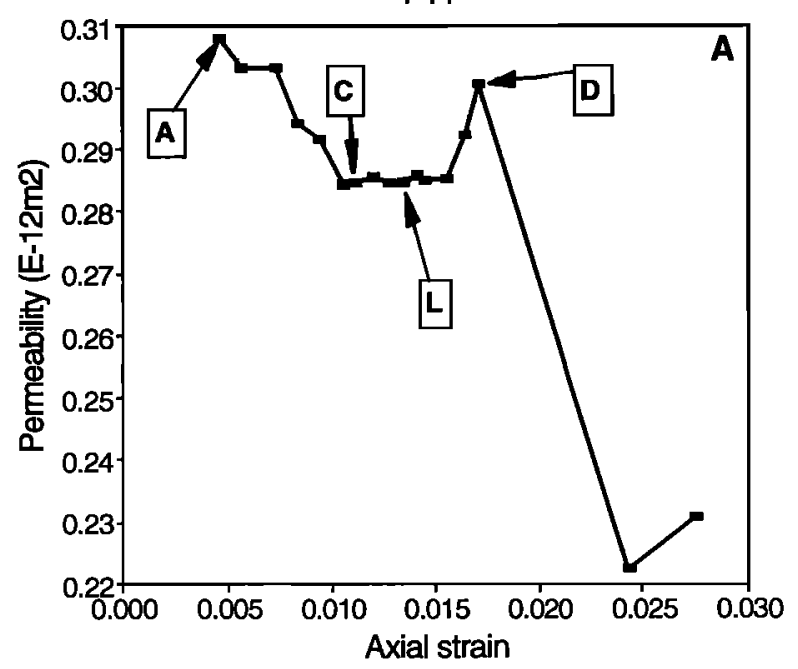

FK5

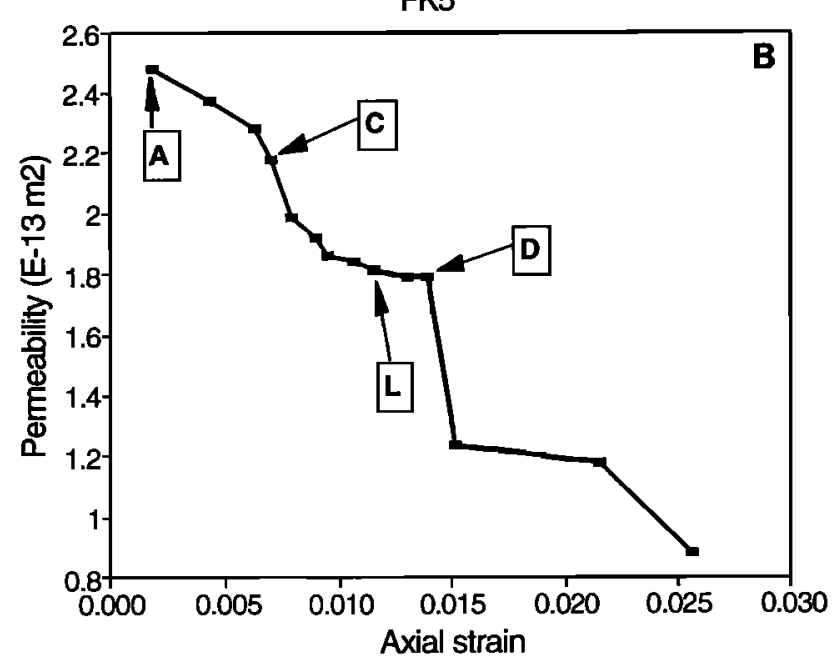

F9IY

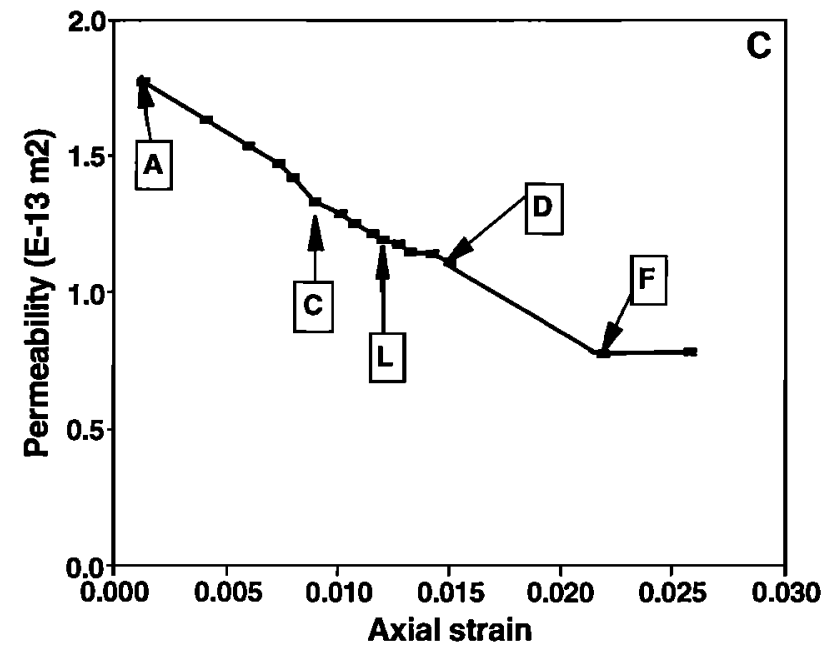

ity, showing that they are not connected. The confining pressure is kept at a constant value (10 MPa) during the experiment to measure permeabilities at the same effective pressure (confining pressure minus pore pressure), as permeability depends on the effective pressure [Brace, 1980]. When failure occurs, the confining pressure often increases by about 1.5-5 MPa. Permeability is then measured when the confining pressure is restored to $10 \mathrm{MPa}$. Hence the drop of permeability is due to the failure and not to an increase of the effective pressure. In all our experiments a drop in permeability is observed when failure occurs. This drop of permeability at failure is about $0.020 \% / 0.1 \mathrm{MPa}$. The grain sizes are reduced during the deformation. At the end of the experiment the connections between the main microcracks, used for the fluid flow, are probably filled with finely crushed particles, inducing the sealing of the main microcracks and preventing the fluid from flowing easily through the sample. Nevertheless, the permeability is not changed by a factor higher than 3 during the entire deformation.

\section{Behavior of the Electrokinetic Coupling Coefficient with Deformation}

A general trend of the behavior of the coupling coefficient is noticeable from point $C$ to failure (point $D$ ). Changes in the electrokinetic coupling coefficient are not similar to changes of permeability. Hence the evolution of the electrokinetic coupling coefficient is not related to changes of the permeability (Figures 10 and 11). Our measurements do not allow us to quantify the pore sizes related to the permeability measured during the deformation. We can not estimate the behavior of the surface conductivity during the deformation. The important variation of the electrokinetic coupling coefficient (reported at a constant fluid conductivity) with deformation results in a decrease from point $\mathrm{C}$ to point $\mathrm{L}$ and an increase from point $\mathrm{L}$ to failure (point $\mathrm{D}$ ) (Figures 10a, 10b, and $10 \mathrm{c}$ ). Point $\mathrm{L}$, representing $72-86 \%$ of the yield stress, may correspond to the onset of the localization of the shear band (it is the growth and the propagation of cracks in an area in which a rearrangement of the grains is observed), and this area will be the way for the future failure. This localization of failure is known to occur after the onset of dilatancy and before failure [Berthaud, 1993]. The important increase of the electrokinetic coupling coefficient from the localization of failure (point $\mathrm{L}$ ) to failure (point $\mathrm{D}$ ) is thought to be due to an increase of $\zeta$ potential in the shear band where new surfaces are created and connected. The $\zeta$ potential is enhanced in the shear zone, and the increase of the electrokinetic coupling coefficient is measured at the sample scale when new cracks are connected (point L) allowing fluid to flow through these new cracks. Also, the creation of a shear zone makes the sample macroscopically heteroge-

Figure 11. (opposite) Variation of permeability with axial strain from triaxial deformation experiment to failure. A indicates the point where samples were subjected to an increasing hydrostatic pressure up to $10 \mathrm{MPa}, \mathrm{C}$ indicates the point of maximum resistivity, $L$ indicates the point of minimum electrokinetic coupling coefficient, $D$ indicates the point of failure, $F$ indicates the end of the first part of the weakening state, and percentages indicate percentages of strength. (a) Results for F44. (b) Results for FK5. (c) Results for F9IY. 
neous. Charge separations may occur across the shear band in addition to the charge buildups at the ends of the sample.

\section{Possible Consequences for Field Measurements}

The major purpose of our study has been to measure representative values of the electrokinetic coupling coefficient under various conditions relevant to geophysical problems. We now give the possible consequences of our results for field measurements. The electrokinetic field due to fluid circulation can be measured horizontally by electrodes on the ground surface or vertically by electrodes buried at different depths.

Surface electrokinetic and magnetic anomalies have been computed in a layered Earth [Fitterman, 1978] and in a faulted half-space [Fitterman, 1979]. It has been shown that a boundary separating regions with different electrokinetic coupling coefficients, with a pressure in excess of hydrostatic at the electrokinetic coupling coefficient boundary, is required to develop a surface self-potential field due to subsurface fluid flow [Nourbehecht, 1963; Fitterman, 1979]. Moreover, these electrokinetic effects are proportional to $\left(C_{1}-C_{2}\right) P$, where $C_{1}$ and $C_{2}$ are the electrokinetic coupling coefficients in region 1 and 2 , respectively, and $P$ is any pressure in excess of hydrostatic at the electrokinetic coupling coefficient boundary. Therefore these electrokinetic effects are changed if $\left(C_{1}-C_{2}\right)$ or $P$ is changed, leading to an electrokinetic potential anomaly.

In order to estimate changes of the difference between the electrokinetic coupling coefficients prior to an earthquake, we have to know the geophysical parameters influencing the electrokinetic coupling coefficient, especially those which could change during the mechanical process of preparation of an earthquake. Figure 12 shows the following (in absolute value). $C$ is proportional to the fluid resistivity, as shown in Figure 6. $C$ is inversely proportional to the fluid viscosity and depends thus on the fluid temperature and on the fluid nature. $C$ is proportional to the $\zeta$ potential and depends on the nature of the rock and of the pore fluid chemistry. $C$ decreases under the effect of the surface conductivity therefore by small pore sizes. $C$ is thus lowered by low permeability and is enhanced by high permeability, as shown in Figure 7. $C$ can increase by a factor up to 650 if permeability increases by a factor $8 \times 10^{3} . C$ depends on the applied deformation, especially between about $75 \%$ of the yield stress and the failure, as shown in (Figures 10a, 10b, and 10c).

We will try to give some applications of the effects of these parameters, especially during the preparation of an earthquake, first in order to measure surface self-potential anomalies in the deformed zone, then to measure these anomalies at large distances from the epicenter.

\section{Measurement of Electrokinetic Potential Anomalies in Deformed Zone}

Dilatancy is commonly assumed to occur prior to an earthquake in the vicinity of the fault, allowing fluid flow variations through the fault and acting as the boundary of the heterogeneity and its vicinity, one side acting as region 1 , the other as region 2 (Figure 13a). The permeability could be enhanced and the electrokinetic coupling coefficient would increase, as the effect of surface conductivity would decrease. The deformation itself could change the rock/fluid

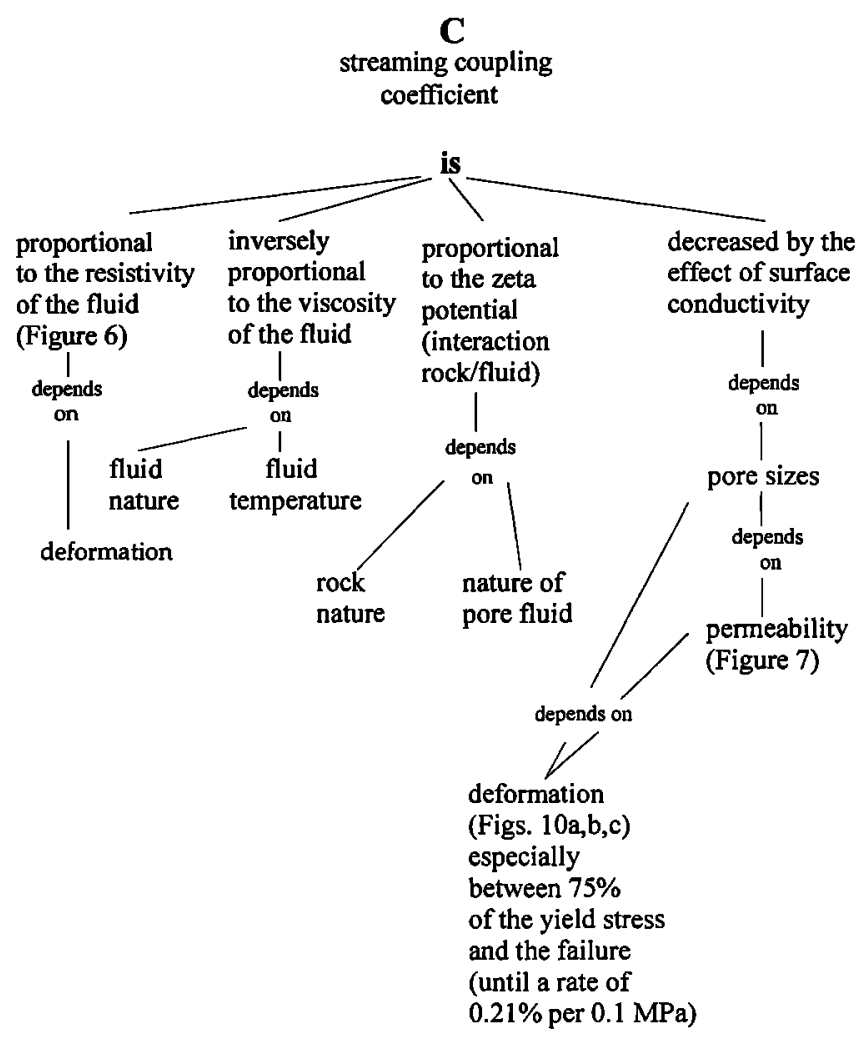

Figure 12. Schematic review of the physical parameters which have an influence on the electrokinetic coupling coefficient.

interaction. For instance, $C$ could increase between about $75 \%$ of the yield stress and the failure at a rate up to $0.19 \%$ for $0.1 \mathrm{MPa}$ of axial stress (Figures $10 \mathrm{a}, 10 \mathrm{~b}$, and 10c), using the effect of deformation on the electrokinetic coupling coefficient measured in our laboratory experiments. In order to measure the maximum of surface electrokinetic anomaly, it will be more convenient to measure the SP anomalies between an electrode buried where $C$ is not changed, and an electrode near the site where a change of permeability is expected, dilatancy is expected, or a change of fluid conductivity is expected, assuming there is a fluid circulation through the fault separating the electrodes.

Miyakoshi [1986] reported SP anomalies at $3.2 \mathrm{~km}$ from the epicenter preceding an earthquake of $M=5.6$, about 40 days and also 55 hours before the earthquake occurrence. The anomaly returned with the onset of the earthquake, reaching the initial level after 13 hours. The electrodes were fixed in an underground observation tunnel, and the maximum of the anomaly was $40 \mathrm{mV}$. He concluded that the anomaly was due to the change of the SP of the fractured fault rock in which one electrode was fixed, the other electrode being at a constant potential serving as a reference. Fluid was flowing through the Yamasaki fault, but this anomaly was not attributed to changes in the water migration through the fault on the basis of the time constant of the anomaly. Our measurements show that another interpretation can be proposed: the electrokinetic coupling coefficient of the rock near the electrode could be changed before the earthquake between about $75 \%$ of the yield stress and the rupture in the seismic zone. As the second electrode has 

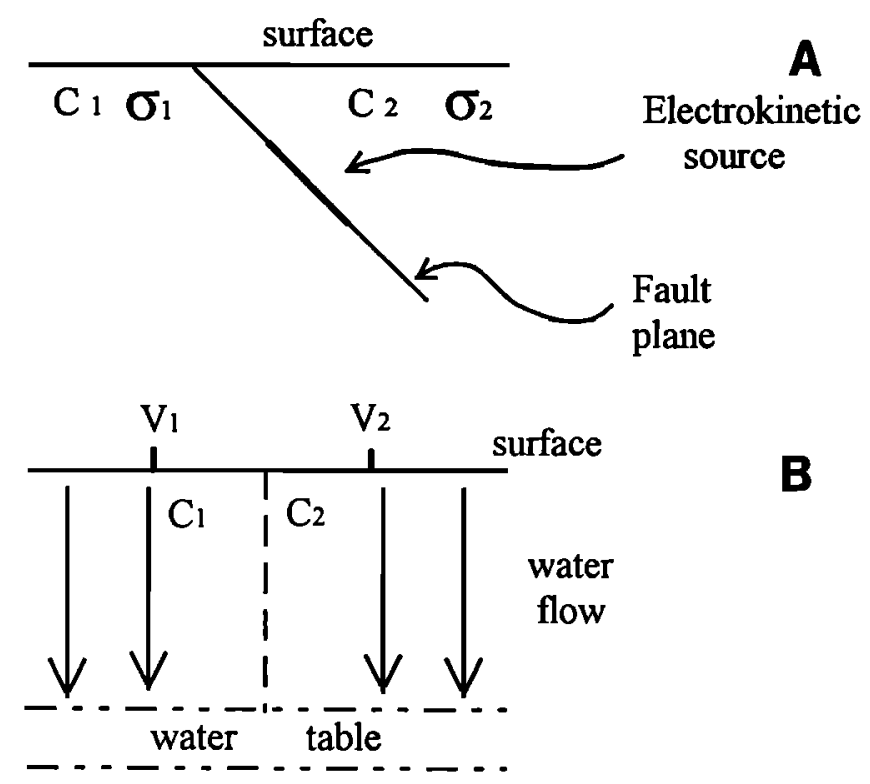

B

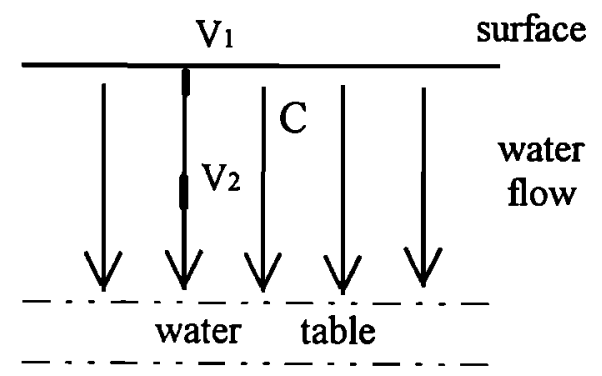

Figure 13. (a) Schematic view of fluid circulation and of lateral heterogeneity of electrokinetic coupling coefficient $\left(C_{1}\right.$ and $\left.C_{2}\right)$ in the vicinity of a fault. (b) Schematic view of vertical fluid flow and lateral heterogeneity of electrokinetic coupling coefficient $\left(C_{1}\right.$ and $\left.C_{2}\right)$ at large distances from the epicenter. $V_{1}$ and $V_{2}$ are the measured electric potentials. (c) Schematic view of vertical fluid flow at large distances from the epicenter, without lateral heterogeneity of electrokinetic coupling coefficient $(C) . V_{1}$ and $V_{2}$ are the measured electric potentials.

shown a constant self-potential, one can suppose that it was buried in a rock with a constant coupling coefficient. Therefore the difference of the coupling coefficient could become greater, leading to an electrokinetic potential anomaly.

\section{Measurement of Electrokinetic Anomalies at Large Distance From the Epicenter}

Anomalies observed at large distances from the epicenter need a different interpretation. Indeed, electrokinetic currents produced in the deformed zone are expected to decrease very rapidly with the distance [Bernard, 1992]. Abrupt upheaval of underground water level is a phenomenon frequently observed postseismically. Large abnormal increases in water flow have been measured in springs and wells, beginning a few days after the seism, especially in major normal fault earthquakes, lasting 6-12 months, and observable at distances of the order of $50 \mathrm{~km}$ from the epicenter. Expelled water volumes were $0.2-0.5 \mathrm{~km}^{3}$ for the two earthquakes studied by Muir-Wood and King [1993] of magnitude 7 and 7.3. The mechanism of such a water expulsion is still controversial, but we can assume that there is ground- water recharge during interseismic periods using the same mechanism. This recharge implies vertical fluid flows in shallow aquifers which could induce electrokinetic anomalies.

These anomalies will be detected at the surface, only if there is a lateral heterogeneity of the values of the electrokinetic coupling coefficient (Figure 13b). Electrokinetic potential anomalies will be proportional to vertical driving pore pressure. Hence any change of the vertical fluid flow could be detected prior to earthquakes. We must notice here that these surface measurements involve nonsaturated medium, and any computation and modeling in this case is beyond the scope of this paper.

Far from the epicenter when variations of the vertical fluid flow exist, the maximum of the electrokinetic effect will be measured between electrodes situated along the flow direction. In this case we assume that the ground is saturated. Thus the measurements will be similar to those made in the laboratory, and a lateral heterogeneity of the electrokinetic coupling coefficient is not needed (Figure 13c). The electric potential difference $\Delta V$ will be directly proportional to the vertical driving pore pressure, as shown in Figure 7, using the effect of permeability on the electrokinetic coupling coefficient measured in our particular laboratory experiments. Therefore an electrokinetic potential anomaly will be measured whenever the following occur. (1) The driving pore pressure is changed (equation (4)). Our measurements show that a streaming potential up to $30 \mathrm{mV}$, for a fluid conductivity of $0.01 \mathrm{~S} / \mathrm{m}$ and a permeability of $10^{-12} \mathrm{~m}^{2}$, could be produced by an underground water level change of $50 \mathrm{~cm}$. Moreover, the streaming potential measurements could indicate when the water level change reverses, as the sign of the streaming potential will be reversed. (2) Fluid resistivity is changed, as the streaming potential is proportional to the fluid resistivity, assuming the driving pore pressure remains constant (4). (3) Permeability between the two electrodes is changed, inducing a different effect of surface conductivity (equation (4)). Our measurements show that if the permeability between the electrodes is increased by an amount of $8 \times 10^{3}$, the streaming potential could be enhanced by a factor of 650 (Figure 7), assuming that the driving pore pressure remains constant.

\section{Conclusion}

Streaming potential was measured along the direction of fluid flow on saturated samples of intact Fontainebleau sandstones. Streaming potential $\Delta V$ is proportional to the driving pore pressure $\Delta P$. For a fixed driving pore pressure, streaming potential is proportional to the fluid resistivity. Electrokinetic coupling coefficient varies from 10 to 6642 $\mathrm{mV} / 0.1 \mathrm{MPa}$ when permeability changes from $0.15 \times 10^{-15}$ to $1220 \times 10^{-15} \mathrm{~m}^{2}$. This has been explained by the effect of surface conductivity which is not negligible compared with fluid conductivity when the permeability is reduced.

When the sample is deformed under triaxial stress up to failure, permeability is changed at the most by a factor 3 . The electrokinetic coupling coefficient $\Delta V / \Delta P$ reported for a constant fluid conductivity of $10^{-3} \mathrm{~S} / \mathrm{m}$ increases from the localization of the shear band up to failure. This increase of the electrokinetic coupling coefficient just before failure is due to an increase of $\zeta$ potential in the shear zone when new surfaces are created and connected.

Possible consequences of our results to investigate the 
electric field which could appear during the preparation of an earthquake have been given. Self-potential anomalies observed in the deformed zone could be due to a large increase of the electrokinetic coupling coefficient from $75 \%$ of the yield stress to rupture. Far from the epicenter when variations of the vertical fluid flow exist in relation to an earthquake our measurements show that a vertical streaming potential of up to $30 \mathrm{mV}$ could be induced by an underground water level change of $50 \mathrm{~cm}$ (for fluid conductivity $0.01 \mathrm{~S} / \mathrm{m}$ and permeability $10^{-12} \mathrm{~m}^{2}$ ). As shown in this paper, the streaming potential is strongly dependent on the permeability. An increase of $8 \times 10^{3}$ in permeability would enhance streaming potential by a factor of 650 . This result could explain the strong influence of the site on the intensity of seismo-electrical signals.

Acknowledgments. This research was supported by ANDRA and the GRECO géomateriaux. It is a collaboration with C. Philippe, ENSAM, Paris. We thank S. Pride for fruitful discussions and the reviewers, D. Fitterman and P. Kasameyer, for their reviews and suggestions. This is ENS contribution 337 and CNRS-INSU-DBT contribution 3, thème Fluides et Failles.

\section{References}

Bernard, P., Plausibility of long distance electrotelluric precursors to earthquakes, J. Geophys. Res., 97, 17,531-17,546, 1992.

Berthaud, Y., Détection expérimentale de la localisation, rapport annuel, Group. de Rech. Coord. géomatériaux, Paris, 1993.

Brace, W. F., Dilatancy-related electrical resistivity changes in rocks, Pure Appl. Geophys., 113, 207-217, 1975.

Brace, W. F., Permeability of crystalline and argillaceous rocks, Int. J. Mech. Min. Sci. Geomech. Abstr., 17, 241-251, 1980.

Brace, W. F., and A. S. Orange, Electrical resistivity changes in saturated rocks during fracture and frictional sliding, $J$. Geophys. Res., 73, 5407-5420, 1968.

Brace, W. F., J. B. Walsh, and W. T. Frangos, Permeability of granite under high pressure, J. Geophys. Res., 73, 2225-2236, 1968.

Corwin, R. F., and D. B. Hoover, The self-potential method in geothermal exploration, Geophysics, 44, 226-245, 1979.

Corwin, R. F., and H. F. Morrison, Self-potential variations preceding earthquakes in central Califomia, Geophys. Res. Lett., 4, 171-174, 1977.

Darve, F. (Ed.), Actes du Colloque Bilan et Perspectives du GRECO Géomatériaux, pp. 19-52, GRECO géomatériaux, Paris, 1992.

Dobrovolsky, I. P., N. I. Gershenzon, and M. B. Gokhberg, Theory of electrokinetic effects occuring at the final stage in the preparation of a tectonic earthquake, Phys. Earth Planet. Inter., 57, 144-156, 1989.

Dukhin, S. S., Surface and Colloid Science, vol. 7, edited by E. Matijevic, John Wiley, New York, 1974.

Fitterman, D. V., Electrokinetic and magnetic anomalies associated with dilatant regions in a layered Earth, J. Geophys. Res., 83, 5923-5928, 1978.

Fitterman, D. V., Theory of electrokinetic-magnetic anomalies in a faulted half-space, J. Geophys. Res., 84, 6031-6040, 1979. (Correction, J. Geophys. Res., 86, 9585-9588, 1981.)

Ishido, T., and H. Mizutani, Experimental and theoretical basis of electrokinetic phenomena in rock-water systems and its applications to geophysics, J. Geophys. Res., 86, 1763-1775, 1981.

Jouniaux, L., Effets électriques et magnétiques liés aux circulations de fluides dans les roches sous contraintes, thèse de doctorat, Univ. Paris 6, 1994.
Jouniaux, L., and J. P. Pozzi, Permeability dependence of streaming potential in rocks for various fluid conductivities, Geophys. Res. Lett., 22, 485-488, 1995.

Jouniaux, L., et al., Resistivity changes induced by triaxial compression in saturated sandstones from Fontainebleau (France), C. R. Acad. Sci., Ser. II, 315, 1493-1499, 1992.

Kondo, D., A. Haied, and J. P. Henry, Detection expérimentale de l'apparition de bandes de cisaillement dans les roches: Mesures extensométriques, rapport scientifique, pp. 219-228, GRECO géomatériaux, Paris, 1991.

Massenet, F., and P. Van Ngoc, Experimental and theoretical basis of self-potential phenomena in volcanic areas with reference to results obtained on Mount Etna, Earth Planet. Sci. Lett., 73, 415-429, 1985.

Merkler, G. P., et al. (Eds.), Detection of Subsurface Flow Phenomena, Lect. Notes Earth Sci., vol. 27, pp. 197-210, SpringerVerlag, New York, 1989.

Miyakoshi, J., Anomalous time variation of the self-potential in the fractured zone of an active fault preceding the earthquake occurence, J. Geomagn. Geoelectr., 38, 1015-1030, 1986.

Mizutani, H., T. Ishido, T. Yokokura, and S. Ohnishi, Electrokinetic phenomena associated with earthquakes, Geophys. Res. Lett., 3, 365-368, 1976.

Morat, P., J. L. Le Mouël, G. Nover, and G. Will, Annual variation of the water saturation of a highly porous rock driven by a seasonal temperature variation and measured by an array of electrodes, C. R. Acad. Sci., 315, Sér. II, 1083-1090, 1992.

Morgan, F. D., E. R. Williams, and T. R. Madden, Streaming potential properties of Westerly granite with applications, $J$. Geophys. Res., 94, 12,449-12,461, 1989.

Muir-Wood, R., and G. C. P. King, Hydrological signatures of earthquake strain, J. Geophys. Res., 98, 22,035-22,068, 1993.

Murakami, H., H. Mizutani, and S. Nabetani, Self-potential anomalies associated with an active fault, J. Geomagn. Geoelectr., 36, 351-376, 1984.

Nourbehecht, B., Irreversible thermodynamic effects in inhomogeneous media and their applications in certain geoelectric problems, Ph.D. thesis, Mass. Inst. of Technol., Cambridge, 1963.

Nur, A., Dilatancy, pore fluids, and premonitory variations of $t_{s} / t_{p}$ travel times, Bull. Seismol. Soc. Am., 62, 1217-1222, 1972.

Overbeek, J. T. G., Electrochemistry of the double layer, in Colloid Science, vol. 1, Irreversible Systems, edited by H. R. Kruyt, pp. 115-193, Elsevier, New York, 1952.

Pride, S. R., and F. D. Morgan, Electrokinetic dissipation induced by seismic waves, Geophysics, 56, 914-925, 1991.

Scholz, C. H., L. R. Sykes, and Y. P. Aggrawal, Earthquake prediction: A physical basis, Science, 181, 803-810, 1973.

Somasundaran, P., and R. D. Kulkarni, A new streaming potential apparatus and study of temperature effects using it, $J$. Colloid Interface Sci., 45, 591-600, 1973.

Stern, O., Zür theorie der electrolytischen doppelschicht, Z. Elecktrochem., 30, 508-516, 1924.

Varotsos, P., and K. Alexopoulos, Physical properties of the variations of the electric field of the Earth preceding earthquakes, I, Tectonophysics, 110, 73-98, 1984a.

Varotsos, P., and K. Alexopoulos, Physical properties of the variations of the electric field of the Earth preceding earthquakes II, Determination of epicenter and magnitude, Tectonophysics, $110,99-125,1984 \mathrm{~b}$.

L. Jouniaux and J.-P. Pozzi, Laboratoire de Geólogie de L'Ecole Normale Supefieure, URA 1316 du C.N.R.S., 24, Rue Lhomond, 75231 Paris Cedex 05, France. (e-mail: jouniaux@magnetit.ens,fr; pozzi@magnetit.ens.fr)

(Received November 22, 1993; revised December 5, 1994; accepted December 29, 1994.) 